\title{
MICROSTRUCTURE AND MECHANICAL CHARACTERISATION OF TIAL COATED ON Ti64
}

\author{
B.N. Masina ${ }^{1}$, T. Lengopeng ${ }^{1}$, S.L. Pityana ${ }^{1,2} \&$ M. Tlotleng ${ }^{1,3 *}$
}

\section{ARTICLE INFO}

Article details

Presented at the $18^{\text {th }}$ Annual International RAPDASA conference held from 8-10 November 2017 in Durban, South Africa

Avaialable online $\quad 22$ Nov 2017

\section{Contact details}

Corresponding author mtlotleng@csir.co.za

Author affiliations

1 Council for Scientific and Industrial Research, National Laser Centre, Laser Enabled Manufacturing, Pretoria, South Africa

2 Department of Chemical, Metallurgical and Materials Engineering, Tshwane University of Technology, South Africa

3 Department of Mechanical Engineering Science, University of Johannesburg, South Africa

DOI

http://dx.doi.org/10.7166/28-3-1854
ABSTRACT

In this study, TiAl alloy was coated on Ti64 using a 1074nm high power continuous-wave laser while varying the laser beam scanning speed. This was done in order to increase the thermo-mechanical properties of Ti64. Scanning electron microscopy (SEM), light optical microscopy, and Vickers' micro-hardness were used to characterise the clad for macrostructure, composition, and hardness respectively. The macro- and micrographs of the clads indicated a needle- and dendritic-rich structure for the clads and widmanstatten structure at the interface for all the scanning speeds. The overall hardness was found to be high at low scanning speed.

\section{OPSOMMING}

TiAl legering is bedek met Ti64 deur 'n 1074nm hoë drywing kontinue-golflaser terwyl die laserstraalskandeerspoed gevarieer is. Hierdie is gedoen om die termo-meganiese eienskappe van Ti64 te verhoog. Skandeer elektronmikroskopie, ligoptiese mikroskopie en die Vicker mikrohardheid skaal is gebruik om die bedekking met betrekking tot die makrostruktuur, samestelling en hardheid onderskeidelik te karaktiseer. Die makro- en mikrograwe van die bedekkings het 'n naaldvormige en dendritiesryke struktuur vir die bedekkings en Widmanstätten strukture by die koppelvlak getoon vir al die ondersoekte skandeersnelhede. Daar is gevind dat die algehele hardheid hoog is by lae skandeersnelhede.

\section{INTRODUCTION}

Titanium and its alloys have been established to be technically superior and cost-effective materials for a range of applications in the industries of aerospace, marine, and even commercial products [1]. This is due to its high strength and excellent corrosion resistance, low density, high strength-toweight ratio, low modulus, and good biocompatibility [2]. Even though it is widely used, Ti64 has limited operating temperature of about $400^{\circ} \mathrm{C}$ [3]. This limits its application in abrasion, wear and cavitation environments [4]. In order to improve on its thermos-mechanical properties, its surface should be modified by surface coating technologies. Ayers [5] demonstrated that the wear resistance of Ti64 can be improved by coating it with titanium carbides and tungsten carbide powders using the laser melt particle injection process. Abbound et al. [6] observed an increase in the microhardness of the melt zone from HV 600 to 650 when SiC was deposited on to titanium alloys.

Laser cladding is one of the laser-based surface modification techniques that is known to be an effective method for improving the wear resistance of titanium alloy surfaces $[1,7]$. This is because it offers profound bonding between the cladded layer and the base material. The process achieves bonding that is metallurgically sound and effective for surface coatings. In addition, this process can achieve a clad layer thickness that can change from few tens of micrometers to a few millimeters. Laser cladding makes use of a high-energy density to prepare an advanced coating on a given base material. The clad is there to protect the engineering components against friction and wear and tear. Molian et al. [8] successfully reduced the wear rates of Ti64 up to two orders of magnitude when 
they laser cladded hexagonal BN powder that was pre-mixed with NiCrCoAlY. Cárcel et al. [4] laser cladded TiAl alloy on Ti64 in order to improve on its operating temperatures. Their results showed that laser cladding TiAl alloy on Ti64 is a suitable technique for the development of thermal barrier coatings. However, this only happens under specific processing conditions, which are always limited by the brittle behaviour of the intermetallic.

TiAl alloys are high temperature intermetallics that can be used for applications in the temperature ranges of about $600-900^{\circ} \mathrm{C}$ [9]. In addition, compared with Ti64, TiAl has several advantages such as high elastic modulus, higher wear resistance, lower density, higher oxidation resistance, and better thermomechanical properties [1]. The objective of this study was to conduct a feasibility study on laser cladding TiAl powders on Ti64 base material. The produced clads were characterised for microstructure, composition, and microhardness.

\section{METHODOLOGY}

TiAl pre-alloyed powder, with a particle size between 45 and $90 \mu \mathrm{m}$, was used in this study for cladding on Ti64 substrates. Multiple tracks of TiAl were cladded on the Ti64 using the IPG fiber laser while varying the laser scanning speed. The schematic diagram of the laser cladding system that was used in this study is given in Figure 1. A $1073 \mathrm{~nm}$ IPG laser was used for the clad. During processing, the laser power $(\mathrm{W})$, laser beam diameter $(\mathrm{mm})$, and power feeding rate $(\mathrm{rpm})$ were kept constant, while the scanning speed was varied from 0.8 to $1.2 \mathrm{~m} / \mathrm{min}$. The laser beam was propagated through optical fibre to the laser cladding head that contains the optical system to focus the beam spot size of $4 \mathrm{~mm}$. A Kuka robot was used for motion control during deposition. In this investigation, laser power of $1 \mathrm{~kW}$ and a power feeding rate of $1.5 \mathrm{rpm}$ were used. Argon gas was used as both carrier and shielding gas. Multiple tracks of 50 per cent overlap were obtained at scanning speeds of 0.8 $\mathrm{m} / \mathrm{min}, 1 \mathrm{~m} / \mathrm{min}$, and $1.2 \mathrm{~m} / \mathrm{min}$ respectively. In order to study the microstructure and microhardness of the clads, metallographic samples were prepared, using standard mechanical polishing methods, and the post polishing samples were etched with Keller's reagent for 2-3 minutes. Olympus light optical microscopy, Joel JSM-6010PLUS/LAM scanning electron microscopy (SEM) with energy dispersive $\mathrm{x}$-ray analysis (EDX) and Zwick/Toel Indetec (ZHV $\mu)$ Vickers hardness were used to characterise the metallographic samples for the microstructure and the mechanical properties respectively.

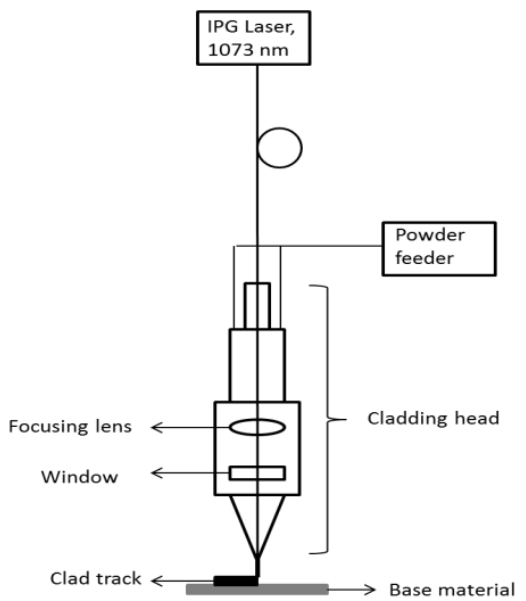

Figure 1: Schematic diagram of the laser cladding system used to clad TiAl alloy powder on Ti64 base material

\section{RESULTS}

\subsection{Microstructure and composition analyses}

Figure 2 shows images of the as-produced clads as the scanning speed was increased. 

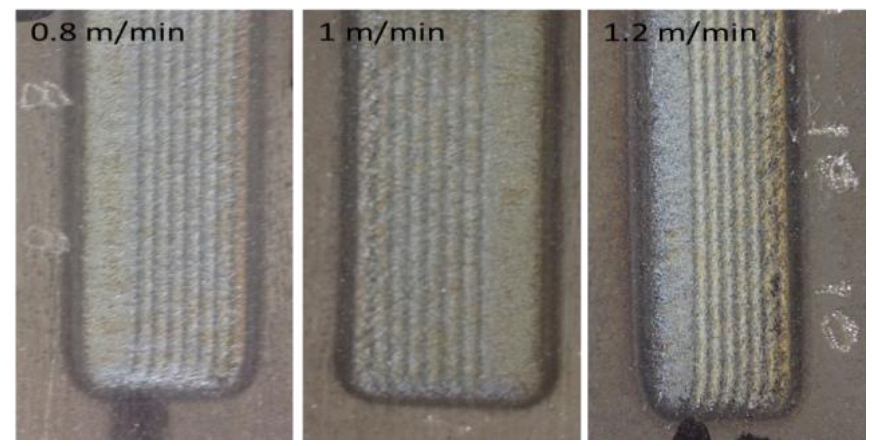

Figure 2: Images of the as-produced clads at the different scanning speeds

The images show no visible cracks, and seem well-bonded. Figure 3 shows an overall optical macroscopy image of the clad, indicating the interface and the heat-affected zone (HAZ).

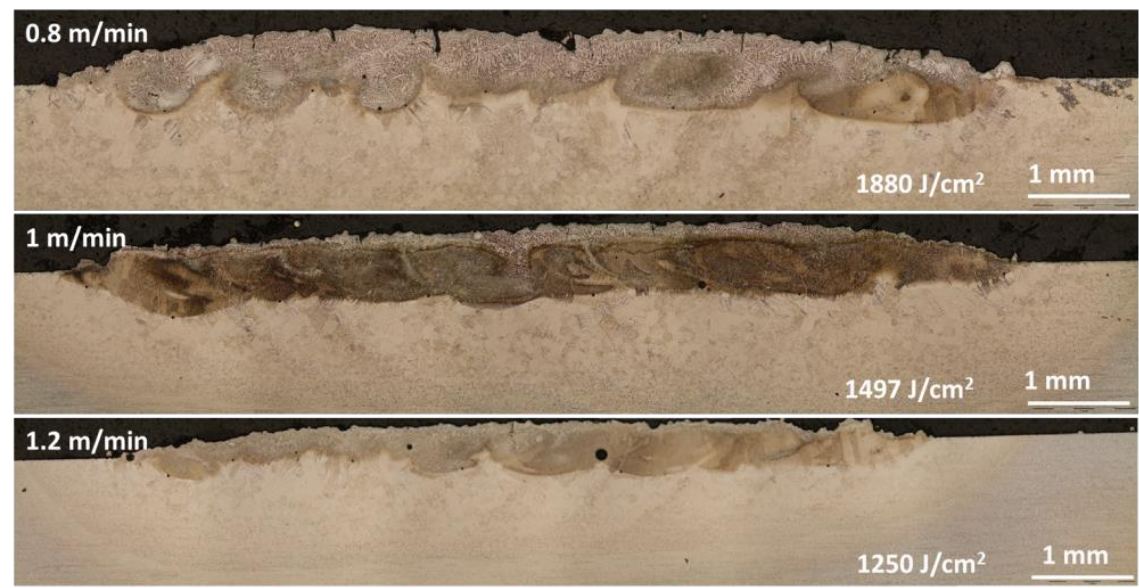

Figure 3: Optical images of the overall image of the clads, interface, dilution, and heataffected zone (HAZ)

Surface cracks with deep penetration into the clads were observed for all samples, as shown in Figure 3. Guo et al. [10] said that this was due to the strong convective flow and surface tension gradient in the melt pool, as well as the TiAl intermetallic compounds, which present low ductility and poor fracture toughness at room temperature [11]. Minimum porosity was also observed in the clad. This may be due to the entrapped gas bubbles, which are due to the large fluid viscosity that is induced by material particles inside the melt pool during the laser cladding process [12]. Figure 3 also indicates the specific energy per laser scanning speed. Overall the clads were well-bonded to the base metal, as seen in Figures 2 and 3. The overall images indicate that the height of the coating was greater at the lower scanning speed, while the HAZ was low at the high scanning speed. This is acceptable, since material-laser interaction time (residence time, s) is increased. Figure 4 shows a typical magnified SEM micrograph and optical macrograph for the produced clads.

The images show the top surface of the clad, interface, and base material. These results confirmed that the clads were well-bonded with the base material, as indicated in Figures 4(a) and (b) respectively. The interface was composed of the widmanstatten structure phase, as shown in Figures 4 (a) and (b) respectively, while the clads were composed of the dendrit structure phase, as indicated in Figure 4(c). SEM-EDS was used to measure the composition of the clads and interface, as the scanning speed was varied. Figure 5 shows a typical SEM-EDS image of the EDS analysis that was done on the clads and on the interface samples. 
(a)

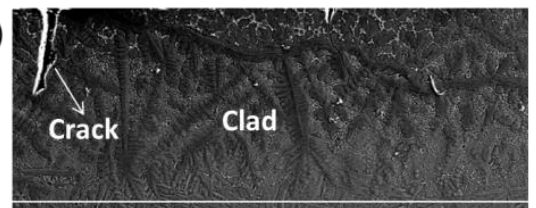

Interface

(b)

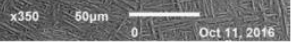

(c)
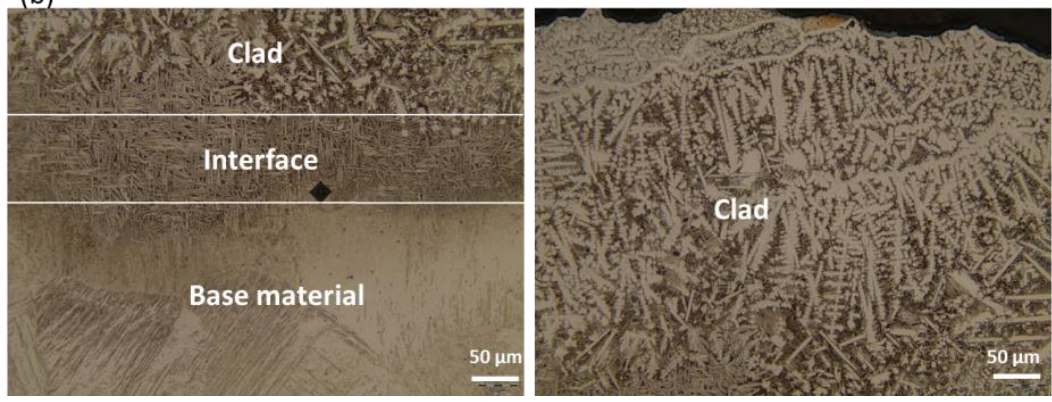

Figure 4: A typical magnified SEM micrograph and optical macrographs for all the clads: (a) clad and interface; (b) clad, interface, and base material; (c) clad
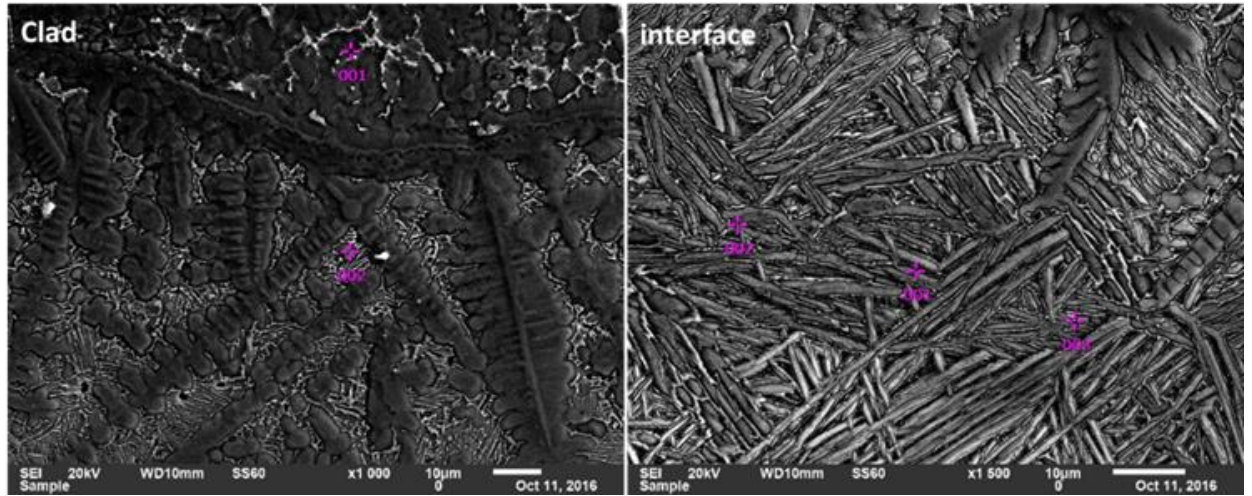

Figure 5: A typical SEM-EDS image showing how the EDS analysis was done on the clad and interface for all the clads

Composition analyses of the clads are shown in Table 1 for the clads. The elemental analyses of the coating are Al, Ti, C, P, and Mo. The carbon in the clad is from the resin. The atomic percentage of $\mathrm{Ti}$ decreased, while Al increased with the higher laser scanning speed. This is acceptable, since a slow scanning speed will lead to increased melt pool temperatures and in turn to evaporation of the aluminum [13]. Table 2 shows the composition analyses, at the interface, of all the clads. The composition elements that were found are $\mathrm{Al}, \mathrm{Ti}, \mathrm{C}, \mathrm{P}$, and $\mathrm{Mo}$. There was little change in $\mathrm{Ti}$, but more Al seems to have migrated towards the substrate (Table 2). This is consistent with the observation that Al decreased with the lower laser scanning speed.

Table 1: EDS analyses of all the clads done in the middle/centre of the clad

\begin{tabular}{|c|c|c|c|c|c|}
\hline \multirow{2}{*}{} & \multicolumn{5}{|c|}{ Atomic \% } \\
\cline { 2 - 6 } & Al & Ti & C & P & Mo \\
\hline Clad 1 - 0.8 m/min & 6.71 & 85.45 & 6.71 & 0.43 & - \\
\hline Clad 2-1 $\mathrm{m} / \mathrm{min}$ & 10.31 & 78.01 & 11.35 & 0.34 & - \\
\hline Clad 3-1.2 $\mathrm{m} / \mathrm{min}$ & 15.69 & 74.58 & 7.15 & 0.65 & 1.93 \\
\hline
\end{tabular}


Table 2: EDS analyses of all the clads done at the interface of the clad and the base material

\begin{tabular}{|c|c|c|c|c|c|}
\hline & \multicolumn{5}{|c|}{ Atomic \% } \\
\cline { 2 - 6 } & $\mathrm{Al}$ & $\mathrm{Ti}$ & $\mathrm{C}$ & $\mathrm{P}$ & Mo \\
\hline Clad 1- 0.8 m/min & 14.11 & 78.28 & 7.60 & - & - \\
\hline Clad 2-1 m/min & 12.93 & 78.25 & 7.74 & 0.38 & 0.7 \\
\hline Clad 3 - 1.2 m/min & 13.61 & 78.15 & 6.72 & 0.46 & 1.05 \\
\hline
\end{tabular}

\subsection{Hardness}

Figure 6 shows the microhardness profile of the clads along the depth direction.

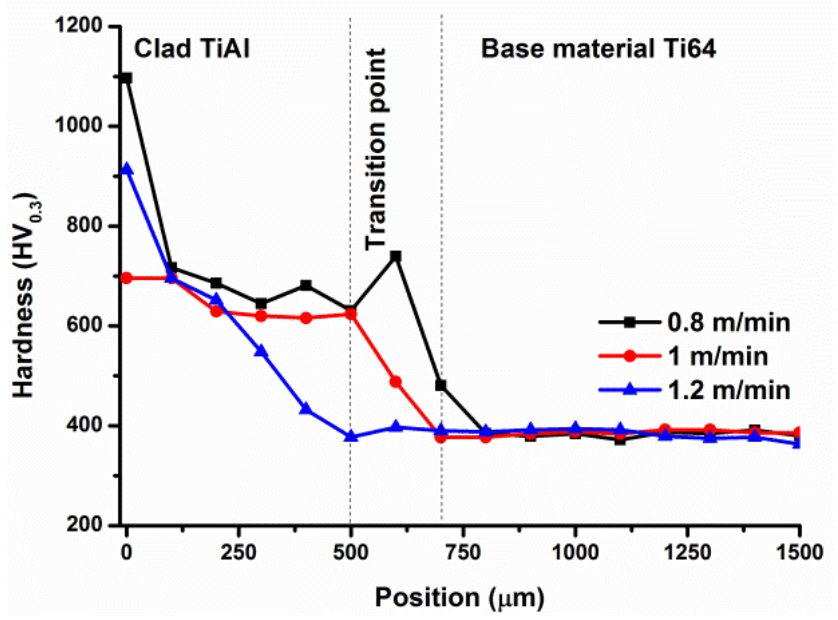

Figure 6: Microhardness graph, indicating transverse hardness of all the clads

The microhardness results indicate that hardness decreases with the increased laser scanning speed. The overall microhardnesses for all the clads were $742.8 \mathrm{HV}_{0.3}(0.8 \mathrm{~m} / \mathrm{min}), 646.83 \mathrm{HV}_{0.3}(1 \mathrm{~m} / \mathrm{min})$, and $648.2 \mathrm{HV}_{0.3}(1.2 \mathrm{~m} / \mathrm{min})$ respectively. This means that, at the lower scanning speed, a harder clad was produced than at fast speeds. This has to do with the laser-material interaction, which could have led to a heat treatment that produced a refined microstructure. Moreover, the resulting heat inputs led to the formation of the dendrites, which increased the material hardness for the 0.8 $\mathrm{m} / \mathrm{min}$ clad. The microhardness profile results taken on the faster scan speed showed a continued decline in the hardness across the surface of the clad. The overall heat input led to a well-bound, high hardness of the clad and HAZ and dendritic structure due to the residence time.

\section{CONCLUSION}

A Couple of clads of TiAl pre-alloyed powder were produced on the Ti64 base material using a laser cladding system. The obtained TiAl clads indicated a dendritic-rich structure for the coating produced with $0.8 \mathrm{~m} / \mathrm{min}$, and a widmanstatten structure phase at the interface. It was found that the HAZ was narrow at a high scanning speed when compared with the slower scanning speed. The main challenge that still needs to be overcome during laser cladding of TiAl pre-alloy powder on Ti64 is the cracking. The microhardness averages for all the clads were determined to be about $742.8 \mathrm{HV}_{0.3}(0.8 \mathrm{~m} / \mathrm{min}), 646.83 \mathrm{HV}_{0.3}(1 \mathrm{~m} / \mathrm{min})$, and $648.2 \mathrm{HV}_{0.3}(1.2 \mathrm{~m} / \mathrm{min})$ respectively. The forming dendrites at $0.8 \mathrm{~m} / \mathrm{min}$ contributed to the reported hardness.

\section{REFERENCES}

[1] Weng, F., Chen, C. \& Yu, H. 2014. Research status of laser cladding on titanium and its alloys: A review, Materials and Design, 58, pp 412-425.

[2] Gogia, A.K. 2005. High-temperature titanium alloys. Defence Science Journal, 55(2), pp 149-173.

[3] Poondla, N., Srivastan, T.S., Patnaik, A. \& Petraroli, M. 2009. A study of the microstructure and hardness of two titanium alloys: Commercially pure and Ti-6Al-4V. Journal of Alloys and Compounds, 486, pp 162167.

[4] Cárcel, B., Serrano, A., Zambrano, J., Amigó, V. \& Cárcel, A.C. 2014. Laser cladding of TiAl intermetallic alloy on Ti6Al4V: Process optimization and properties. Physics Procedia, 56, pp 284-293. 
[5] Ayers, J.D. 1984. Wear behavior of carbide-infected titanium and aluminum alloys. Wear, 97(3), pp 249266.

[6] Abboud, J.H. \& West, D.R.F. 2013. Ceramic-metal composites produced by laser surface treatment. Materials Science and Technology, 5(7), pp 725-728.

[7] Cai, L.F., Zhang, Y.Z. \& Shi, L.K. 2007. Microstructure and formation mechanism of titanium matrix composites coating on Ti-6Al-4V by laser cladding. Rare Metals, 26(4), pp 342-346.

[8] Molian, P.A. \& Hualun, L. 1989. Laser cladding of Ti-6Al-4V with Bn for improved wear performance. Wear, 130(2), pp 337-352.

[9] Wu, X. 2006. Review of alloy and process development of TiAl alloys. Intermetallics, 14(10-11), pp 11141122.

[10] Guo, C., Zhou, J.-S., Zhao, J.-R. \& Chen, J.-M. 2011. Improvement of the tribological properties of pure Ti by laser cladding intermetallic compound composite coating. Proceedings of the Institution of Mechanical Engineers, Part J: Journal of Engineering Tribology, 225(8), pp 864-874.

[11] Gschneidner, K., Russell, A., Pecharsky, A., Morris, J., Zhang, Z., Lograsso, T., Hsu, D., Lo, C.H., Ye, Y., Slager, A. \& Kesse, D. 2003. A family of ductile intermetallic compounds. Nature Materials, 2(9), pp 587-590.

[12] Guo, C., Zhou, J., Chen, J., Zhao, J., Yu, Y. \& Zhou, H. 2010. Improvement of the oxidation and wear resistance of pure $\mathrm{Ti}$ by laser cladding at elevated temperature. Surface Coatings Technology, 205(7), pp 2142-2151.

[13] Wang, G. \& Dahms, M. 1993. Synthesizing gamma-TiAl alloys by reactive powder processing. JOM, 45(5), pp 52-56. 